\title{
An integrated project of entrepreneurship and innovation in engineering education
}

\author{
Filomena O. Soares ${ }^{\mathrm{a}, *}$, Manuel J. Sepúlveda ${ }^{\mathrm{a}}$, Sérgio Monteiro ${ }^{\text {a }}$, Rui M. Lima ${ }^{\mathrm{b}, \mathrm{c}}$, José Dinis-Carvalho ${ }^{\mathrm{b}, \mathrm{c}}$ \\ ${ }^{a}$ RED Algoritmi Centre, Campus de Azurém, 4800-058 Guimarães, Portugal \\ ${ }^{\mathrm{b}} \mathrm{RED}$ CGIT Centre, Campus de Azurém, 4800-058 Guimarães, Portugal \\ ${ }^{\mathrm{c}}$ Dep. of Production and Systems Engineering School, University of Minho, Campus de Azurém, 4800-058 Guimarães, Portugal
}

\section{A R T I C L E I N F O}

\section{Article history:}

Available online 28 September 2012

\section{Keywords:}

Project-based learning

Mechatronics education

Multidisciplinary team

\begin{abstract}
A B S T R A C T
This paper presents a new line of project based learning in the School of Engineering of University of Minho: the Innovation and Entrepreneurship Integrated Project (IEIP). Four groups, each one composed of students from different engineering integrated master courses - Mechanical, Industrial Electronics and Computers, Polymer, Industrial Management - compete against each other in developing or improving commercial products manufactured by actual industries. There have been so far five editions of the IEIP, with five different companies and five diverse products, however, all these products included components that required knowledge from all the engineering courses involved. Only with the cooperation between the students of the various courses that compose each multidisciplinary team, the success is attainable. As each student has to deal with various engineering scopes, students' technical skills are greatly enlarged and they acquire a multidisciplinary knowledge that was not possible in another way. Their soft skills like project management, teamwork, communication ability and personal development, which are valuable requisites for their future employers, are also improved. The participating industries also take advantage of the project: the groups competing against each other act as a multiskilled work force, actually making proposals capable of improving their products, their efficiency, and reducing costs.
\end{abstract} (c) 2012 Elsevier Ltd. All rights reserved.

\section{Introduction}

Student centered learning methodologies have gained force in European high education institutions. In particular, engineering courses are a good example of successful applications of project based learning (PBL) approaches [1]. These project approaches include designing, solving, and improve solutions for real-world problems; a key goal for engineering students.

At the University of Minho several programs have been applied to support new experiences of active learning aiming to prepare students to solving problems usual found in industrial environment. Following this trend, Industrial Engineering and Management course of the University of Minho has been applying the Project Led Education (PLE) approach [2] since 2004/2005. In this model each students' team develop a common project for the whole semester. In this project they should develop competencies of all curricular units (CU) of the semester in an integrated way. The project has two objectives: apply CU contents in the proposed task and contribute to a deeper comprehension of those contents.

\footnotetext{
* Corresponding author. Tel.: +351 253510180; fax: +351 510188.

E-mail addresses: filomena.soares@algoritmi.uminho.pt (F.O. Soares), mjs@dei.uminho.pt (M.J. Sepúlveda), smonteiro@dei.uminho.pt (S. Monteiro), rml@dps.uminho.pt (R.M. Lima), dinis@dps.uminho.pt (J. Dinis-Carvalho).
}

With the adoption of this methodology [3] the students develop several competencies: Knowledge, Skills and Attitudes. Problembased learning uses real world problems to motivate students to identify and apply research concepts and information.

The acquired experience on PLE approach motivates the extension of this methodology to other experiences involving other programs in the School of Engineering. Real world problems in mechatronics industries need knowledge integration, putting together different areas and expertise. Following this trend, a new approach integrating students from different courses in a unique curricular project, arose: Innovative and Entrepreneurship Integrated Project (IEIP). IEIP runs for 5 years. In the first experience, in 2007/2008, there was the integration of Industrial and Management Engineering (IME), Polymer Engineering (PE) and Industrial Electronic and Computers Engineering (IECE) [4]. In the following year there was the integration of Mechanical Engineering (ME) and in 2009/2010 the participation of Architecture course (ARQ). The last two editions, $2010 / 2011$ and $2011 / 2012$, had the same course composition of the second one. IEIP goal is to have an approximate replica of what students will find when getting a job in an engineering related industry. In IEIP, students integrate a multidisciplinary working team; they work directly with an industry that defines project requisites. This environment is special important for engineering students where mechatronic applica- 
tions need the intervention from mechanical, electronics and production subjects.

The objective of this paper is to describe and evaluate an innovative approach of project based learning which integrates four to five courses of the University of Minho, including mechatronics' requirements.

The paper is organized in six sections as follows: Section 1 introduces the subject; Section 2 presents a broad view on project based learning methodology; in Section 3 it is presented the Innovative and Entrepreneurship Integrated Project; Section 4 details the proposed projects; and Section 5 summarizes IEIP evaluation from students and teachers; finally, some concluding remarks are presented in Section 6.

\section{Project-based learning methodology}

The development of engineering competences requires the application of technical knowledge in specific contexts linked to the professional practice. Further, according to the UNESCO report [5] the engineering practices also requires the application of transversal competences, e.g.: autonomy; leadership or interaction with others in interdisciplinary teams; negotiation or solving conflicts; communication in effective ways; project management. Some examples of learning processes closer to the professional experience in higher education have resulted primarily from practical training in final years of formation or even after the end of initial formation. However, it can be argued that following this approach, students may lose the possibility to develop these competences integrating academic technical knowledge with professional knowledge.

Some authors have described examples that exploit the potential advantage of developing these competences in a more integrated way in engineering programs: industrial training periods in the early years [6]; project based learning (PBL) processes close to the professional practice [3,7-9].

Project led engineering education, a specific approach to project-based learning is focused on the integration of several knowledge areas for solving a problem linked to real situations, during a long period of time (e.g. a semester), resulting in a specific final result $[2,9]$. This learning methodology requires application of competences that can be characterized as "how to make", i.e. it is necessary to apply knowledge in practical contexts. This is a methodology intrinsically linked to the development of technical and transversal competences. According to several authors $[2,3,9]$, some of the main transversal competences developed by students are: time management, project management, inter-personal communication and autonomy. The formation of engineers with transversal competences makes sense if they are integrated with key technical competences. This will lead to engineers capable of designing, developing and evaluate products or systems, with appropriate technical characteristics and functions for solving real problems $[5,10]$. It is further assumed that the engineers are able to operate and maintain the functioning of systems that integrate people and technology. This methodology creates a learning environment closer to the professional practice.

An approximation between higher education training and the professional world was reported by Harrison et al. [11] for an experience involving hydropower engineering students in various courses. In that experience it was created groups with students from four engineering courses, including: Electrical, Mechanical, Civil and Chemical. These students had the opportunity to select one of three projects: Hydropower, Potable Water Supply and Microsystems. The authors focus their analysis on the project which was the most competitive of designing a Central Power Plant, with groups of 6-7 with a balanced number of elements of each of the following courses of Engineering: Electrical, Mechanical and Civil. The most successful teams were those that worked with a project leader with well-defined functions of project manager, presenting an overview of objectives and project activities. This project had a load equivalent to one third of a semester and was evaluated positively by students, faculty and accreditation teams. The authors summarize the following aspects as critical to the success of this type of experience: students from different courses must feel the usefulness of their contribution which was made possible with this project, should avoid an imbalance in the number of students in each course for avoid marginalization of the most isolated, should engage teachers in all subject areas to give adequate support to the project.

Following this trend, a new project based learned was designed and implemented in University of Minho 5 years ago. Next sections are devoted to presenting project goals, methodology, target realworld projects and results.

\section{Innovation and Entrepreneurship Integrated Project}

The Innovation and Entrepreneurship Integrated Project (IEIP) aims to develop the entrepreneurship competencies in the "enterprising person" sense as described in [12]. In this sense it is expected that students develop the ability to be creative, to have initiative, to have the ability to take decisions, to do and conclude activities, demonstrate leadership and "do things" in different and unexpected ways. The open projects assigned to IEIP editions are adequate to create the ground were these competences and abilities are expected to be developed by students. Students are expected to apply courses' required contents in the project. In this way students develop the ability to manage tasks over the time with several available resources. Furthermore, they will be interacting with industrial organizations interested in the project's results. Apart from the technological objectives, IEIP have the following general objectives:

- Develop team work competences.

- Develop initiative and creativity.

- Develop the ability to take decisions.

- Develop communication abilities.

To satisfy industrial requirements, developing technical competencies - from CUs supporting the project - and also the transversal competencies referred before, students must be creative and apply technical knowledge to solve real problems [4]. In order to achieve this, students must be able to manage the project and deal with time management, workgroup, and communication issues.

Creating the opportunity to develop these competencies will make a contribution for the development of entrepreneurship attitudes through engineering curricular structures. This perspective of integration with the curricular structure is promoted by the European Community [13].

An integrated master course is composed of five academic years and 360 ECTS (European Credit Transfer and Accumulation System). This project is integrated in the course curriculum normally at the seventh semester with typically 10 ECTS corresponding to $280 \mathrm{~h}$ of project work. The predefined amount of ECTS allocated to the project that is related with one or more curriculum units (CU) of each course.

The IEIP Project is managed by a team of teachers from the $4 / 5$ courses and also by some researchers from the educational field. This team is coordinated by one of the teachers, and this function is rotated every year.

The students participating in the IEIP project are selected, from the list of candidates, according to criteria specified by the course coordinator. Eight students from each one of the 4 or 5 courses are selected. The students that are not participating in this project with 
be participating in other more traditional projects predefined in each particular course.

On the IEIP kick off meeting, normally on the first day of the semester, all selected students are present as well as the IEIP coordinating team and the company representatives. In this session the project objectives are presented by the company representatives as well as the overall planning with the most important milestones. The students are then grouped in four teams with two students from each different integrated master course in each team. In most editions each one of the four teams was composed by two students from Mechanical Engineering, two from Polymer Engineering, two from Industrial Engineering and two from Electronic Engineering. To each team is assigned a project room where the team can spend $24 \mathrm{~h}$ per day and where the store their materials and personalize it as they wish. Normally the students spend long hours in their project room, especially on the weeks before presentation or other milestones and at later stages of the semester. Tutors (one per team) are teachers assigned to supervise the team work not in technical terms but in terms of project management, team management and problem solving. The tutor main role is to monitor the team work, give some level of guidance to solve problems, and prevent as far as possible irreversible problems in the team. Teams meet teachers from different technical competences as needed and also in normal scheduled tutorial classes assigned previously to different technical courses. Moreover, meetings with all teachers at the same time in the same class room are planned as milestones to tackle problems such as technical integration, team management, scope and schedule. Other opportunities to meet teachers are the public presentations taking place 3 times along the semester where each team presents the projects progress and get feedback from colleges, teachers, tutors, company representatives and from other staff members. In terms of interaction with the company where the project is undertaken, student teams and company representatives establish the terms for visits and appointments and the rules for communication.

\subsection{How IEIP works}

IEIP is running for 5 years. The main format includes two students from different courses of the Engineering School at University of Minho: 4th year of Industrial and Management Engineering (IME); 4th year of Polymer Engineering (PE) and 4th year of Industrial Electronics and Computers Engineering (IECE). Depending on the project specification and needs other courses can be included. Each year four groups (having 6-10 students each) are competing in IEIP, designing a new product or improving an existing one, or even proposing changes to the production systems. The students participate in IEIP in a voluntary basis, but after choosing to join the project, the students cannot quit.

In the academic year $2007 / 2008$, the IEIP project worked for the first time with four groups of six elements (see Fig. 1a). The project was developed in cooperation with the PROHS Company and consisted in developing a new bench sterilizer.

In the academic year 2008/2009, the IEIP project ran for the second time. As in the first edition the participating students felt lack of mechanical support, the Mechanical Engineering (ME) course was invited to participate (see Fig. 1b). The project was developed in cooperation with the Petrotec Company and consisted in optimizing a new fuel pump.

In the academic year 2009/2010, IEIP project was in its third edition. As the project was a Galp Contest to develop a Hotspot (Gas Outdoor Heater), design was an important issue, so the Architecture (ARQ) course was invited to participate in this IEIP edition. In the Polymer Engineering course there was also an alteration: starting from this year, the PE students were from the 5th year (see Fig. 1c).

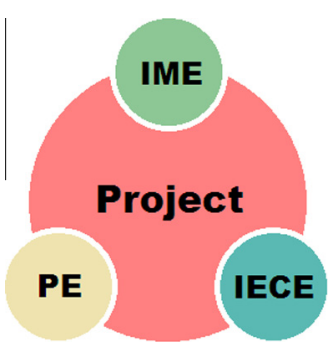

Fig. 1a. Constitution of IEIP (first edition).

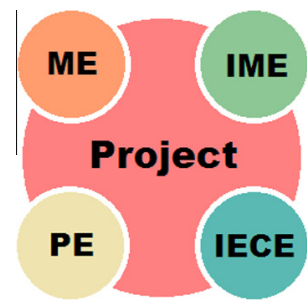

Fig. 1b. Constitution of IEIP (second, fourth and fifth editions).

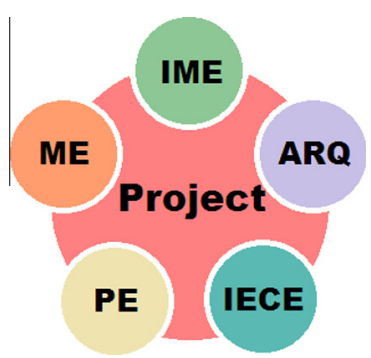

Fig. 1c. Constitution of IEIP (third edition).

The IEIP's fourth edition was in the academic year 2010/2011. It ran in the same configuration as in the second edition (see Fig. 1b). The project was done in cooperation with the Moldartpóvoa Company and consisted in developing new frames from new materials and optimizing its production layout.

The fifth edition of the IEIP project was in the academic year 2011/2012. The configuration was maintained (see Fig. 1b). The project was done in cooperation with the Hydracoolimg Company and consisted in developing a new high efficiency commercial display refrigerator.

The skills that students must acquire in this interdisciplinary project are largely the specific skills they should acquire when performing the various curricular units that make up the first semester of 4th year of each of the five courses involved. These skills are in the case of students from IME, most of the skills expressed in the CUs of Information Systems for Production, Simulation and Integrated Production. In the case of students from IECE and PE are the technical competences to be acquired are related to Project Unit. For students from ME, these skills are those of the CUs Theory of Mechanical Design and Integration Unit VII. For students in ARQ, the skills developed are relevant to $\mathrm{CU}$ Atelier $1 \mathrm{~B}$, with a contribution to Seminar 1B.

Group work in a multidisciplinary project provides unique moments of learning. In addition to the expertise of the technical skills represented in the project, students have the opportunity to develop a set of soft skills, which are a central aspect of the project work. Participation in a project of this nature creates opportunities for the development of soft skills that students need to develop and operate over their respective course. This project focuses on developing soft skills such as project management, teamwork, 
communication skills and personal development, which are valuable skills for employers.

Students receive also additional training, from TecMinho in the areas of entrepreneurship and industrial property in order to develop their skills based on existing mechanisms for the creation of enterprises and introduction of new products. TecMinho is a private non-profit association, having as sponsors the University of Minho and the Association of Municipalities of Vale do Ave. It is an interface of the University of Minho, promoting the connection to society, especially in the areas of science and technology, contributing to regional development (http://www.tecminho. uminho.pt/).

Each group has a tutor who is selected among the teachers involved in IEIP. The group (tutor included) meets at least once a week; all the meeting outcomes are registered in a book. There are also several control points (milestones) to control the progress of projects, while retaining some freedom of action between groups. Compliance with these control points is required for the groups to get final approval. All documents produced must be submitted electronically to the coordinating team for evaluation.

The groups have a dedicated room all over the semester as well as a portable computer with Internet access.

Moodle platform (http://moodle.dps.uminho.pt/) supports the project, making available or promoting:

- The content of courses and students.

- The information on the organization of the project.

- Teamwork by using Chat and Forum.

- Chances of contact for clarification and answer questions.

- Lists of answers to frequently asked questions.

- Quick access to all members, students and/or teachers.

\subsection{Technical competences in IEIP}

Besides the referred soft skills that students explore throughout project development, there are specific technical skills students must accomplish. In particular, each course defines its main objectives in IEIP.

IME students are expected to acquire competences on:

- Relating organizational functions and techniques of Computer Integrated, Manufacturing, Production Management and Planning and Production Control.

- Recognizing the need and objectives for the use of methodologies for analyzing and Planning Information System, and applying the acquired skills on planning and analysis of information systems to systems planning and production control.

- Interpreting and analyzing the behavior of a real system (production system).

IECE students are expected to acquire competences on:

- Implementing and developing the fundamental techniques of the analysis and design of devices and electronic systems.

- Implementing process automation, automatic control and signal processing systems; systems for sensing and actuation; programming.

- Analyzing the fundamental concepts of industrial processes and systems.

ME students are expected to acquire competences on:

- Applying the philosophies of traditional and advanced mechanical design: design methodologies, design for manufacturing, assembly and maintenance.
- Analyzing and promoting the planning, organization and economic aspects related to design and product development.

- Modeling and simulating computationally and numerically.

PE students are expected to acquire competences on:

- Analyzing, modeling and designing systems of Polymer Engineering, by rehearsing, evaluating and ensuring the quality of components and products.

- Designing and manufacturing plastic products and equipment in industrial sector.

- Approaching experimental problems.

- Integrating sustainable development practices and environmental preservation and restoration in the design and production of plastic components.

ARQ students are expected to acquire competences on:

- Selecting specific tools for Research on Sustainability.

- Assessing Sustainability and Environmental Quality of a building system/component.

- Resolving exercises and specifying the form of drawings, writings and demo/virtual models.

There are common items in all courses' objectives, namely: understanding and analyzing the behavior of a real production system and also sustainable and environment concerns.

Other topics are specific of each course. In particular, monitoring systems and process control technical competences are fulfilled by IECE curriculum. It is worth mention that in all IEIP editions, the competencies regarding process monitoring and control are fundamental for project success. In fact, in industrial projects, independently of their dimension, there is a need for sensor systems and automatic process development.

\subsection{Students assessment}

In general, IEIP evaluation has many components: it consists of reports assessment, preliminary report (30\%) and a final report (20\%), three public presentations of the work (20\%) and the prototype evaluations (30\%).

Sometimes, due to the project specifics, there were some minor variations. For example, in the third edition of the IEIP, there were two more reports than usual and a $5 \%$ bonus for the group(s), that passed to phase 2 in Galp contest. Fig. 2 shows the IEIP Evaluation Grid performed by all IEIP teachers in the third edition, where there were four reports and a $5 \%$ bonus.

The assessment is performed by the coordination team which includes every course coordinator, tutors and company representatives. Peer assessment in the team is also envisaged in the assessment system and always suggested and encouraged to be used by student teams. In this way the grades may not be exactly the same to every team member.

\section{Proposed projects}

The proposed projects are rather complex, do not have a unique solution and should be challenging both for students and for teachers. Furthermore, in its completion students must develop the learning skills of the curricular units directly involved in the project as well as other skills both technical and transversal.

In this project, students submitted proposals for new product design and/or improvement as well as for the production system performance improvements. In most cases the objectives defined by the coordination team in accordance to the company, for 


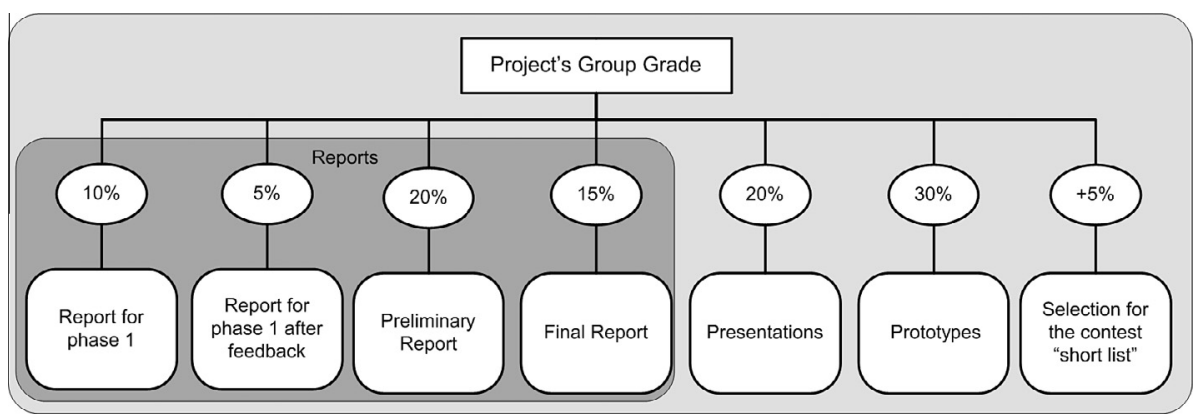

Fig. 2. Assessment grid for third edition of IEIP (Galp contest).

student team to reach, are reduction of materials and production costs, reduction on size or weight, and in general make the product more competitive in the market. These improvements had to be properly justified, according to the assessment criteria previously defined.

\subsection{7/2008 year: description and objectives}

The company involved in this project, PROHS, is dedicated to the manufacture of hospital and sterilization equipment branded JSM (http://www.jsmonteiro.pt). This partnership seeks to obtain proposals for improving a bench sterilizer and its production system in order to make it more competitive in the market. The bench sterilizer is used in small clinics and doctors and should be placed on a bench (see Fig. 3). Design changes are recommended to their current placement and manner of operation. According to the perception of the company this factor has negatively influenced the marketing of the product. In addition, due to its complex structure, the widespread use of stainless steel and the electronic components used, contribute to the products high end cost. The company had these main objectives:

- Reducing the cost of the components.

- Reducing the production costs.

- Creating a new and more attractive design.

All the four groups came up with large number of interesting proposals to achieve the defined objectives. The most common proposals were of the following types:

- Replacing components by using other less costing materials.

- Using other materials to reduce production costs.

- Using new production organization to reduce production costs.

- Applying different and more effective and cheaper isolations materials to reduce costs and save energy consumption.
- Improving the door closing system making it more user friendly.

- New external design to improving the appearance.

Fig. 4 presents two examples of proposals concerning the external appearance of the developed sterilizers.

\subsection{8/2009 year: description and objectives}

The company involved in this project, PETROTEC (www.petrotec.pt), is dedicated to the manufacture of various types of service stations related products, among which stand out the fuel pumps and washing machines. The company proposed the focus on their most advanced product, the P5000 Fuel Pump (see Fig. 5). This approach makes sense in that, being multi-disciplinary groups, suggestions for effective product improvement and cost reduction may be found, concerning the various technologies and modules of the P5000 fuel pump. As the product is still in the industrialization it may therefore incorporate those suggestions.

To achieve these objectives it will be necessary to analyze the product and its production system:

- Characterize, classify, and evaluate the production system performance.

- Characterize and classify the organizational structure.

- Identify the main planning and production control functions, how they relate to each other and the processes and techniques currently used to implement it.

- Identify the used information and its streams.

- Assess how the computer systems are implemented to satisfy the functional requirements and production system information.

- Define possible action alternatives and expected results.

- Analyze the existing product, listing its product components and identification of its function.
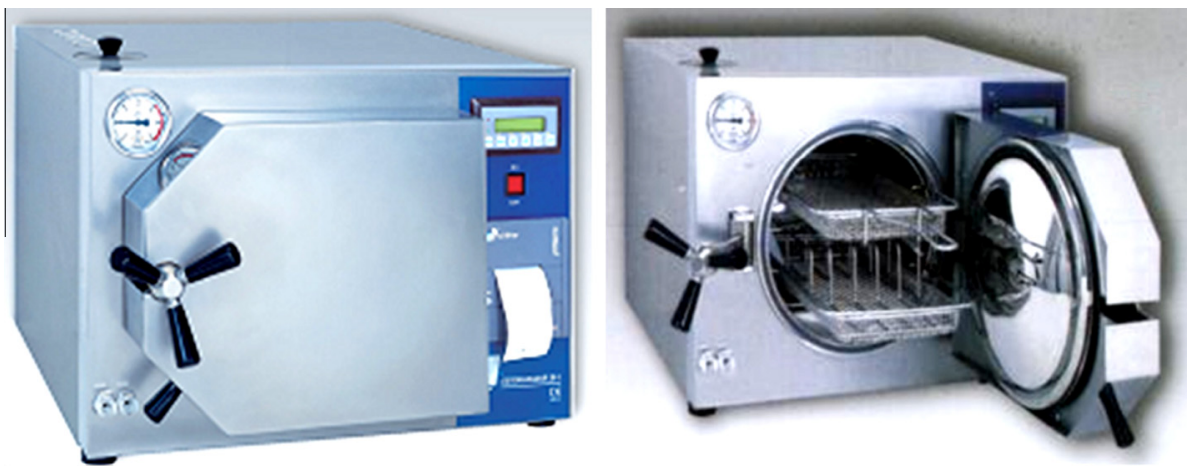

Fig. 3. Bench sterilizer. 

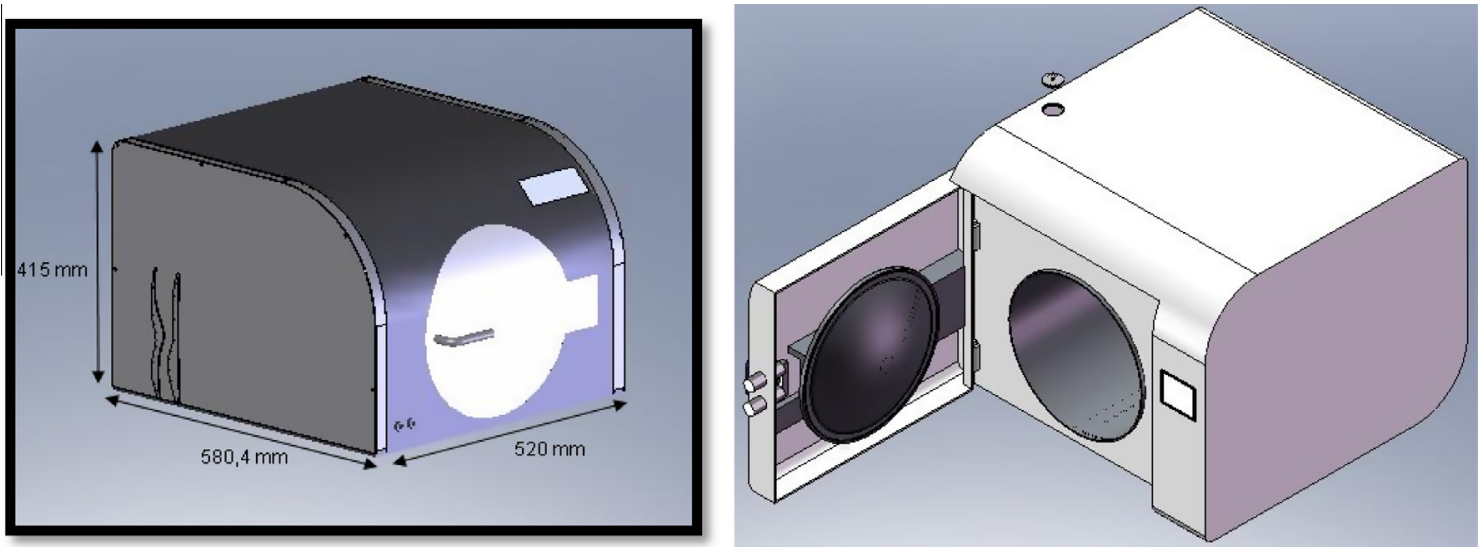

Fig. 4. Two proposed Bench sterilizers.

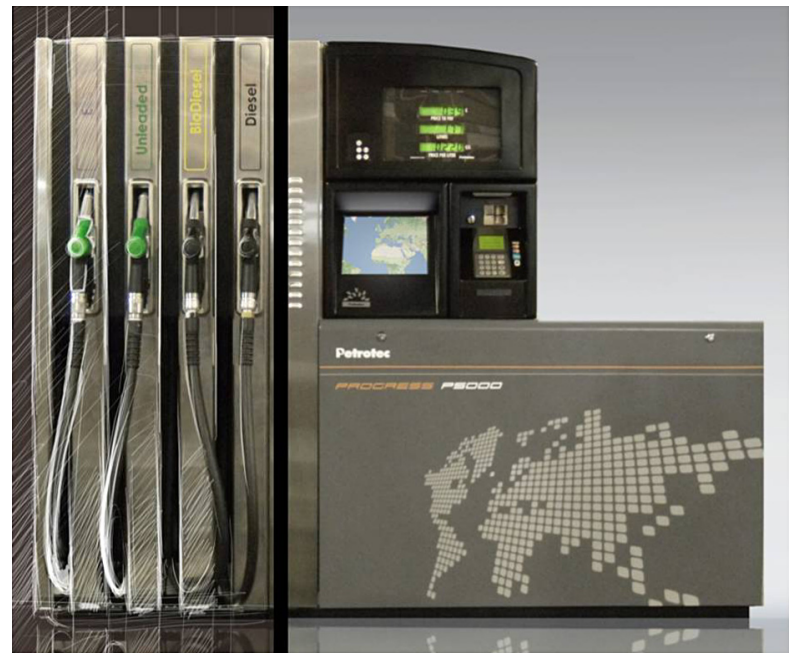

Fig. 5. General appearance of the P5000 fuel pump.

- Designing, evaluating and selecting new workarounds for the product concerned.

This analysis would serve as a basis for improvements proposals through:

- Model selection techniques used in production planning and control, and information structures specification.

- Specifying new performance goals.

- Implementing new organizational solutions for the production.
- Specifying the appropriate information system to the new planning and production control system.

- The selection of the best alternatives.

- Conceptual design effort focused on components detail, materials, geometries, production methods, assembly process and maintenance.

Fig. 6 presents some proposed innovations for the fuel pump.

\subsection{9/2010 year: description and objectives}

In 2009/2010 edition, IEIP groups participated in the contest "Hotspot design" hosted by GalpEnergia.

In order to promote the use of terraces outside the summer period, several coffee shops start using terrace heaters. Each of these heaters is used to warm the place of four tables on average, which for increased efficiency, have to be combined with other equipment, including: wind barriers and sun shades. Despite the satisfaction expressed by GalpEnergia customers with the available Galp hotspots (see Fig. 7), both in terms of aesthetics and efficiency of the device, the company intends to offer another type of heater, which is distinct in design and at a reduced price. With this goal, GalpEnergia Company launched a national contest for a new hotspot. GalpEnergia provided all the information on the website (market research, surveys, pilot testing, and other actions). Multi-disciplinary teams and interaction between competing teams were valued.

The prizes to be awarded to the winning application were:

- A $20,000 €$ reward.

- Members of the winning application joined the "GalpEnergia Fellowships" (exclusively for University Students with training in the areas eligible to contest).
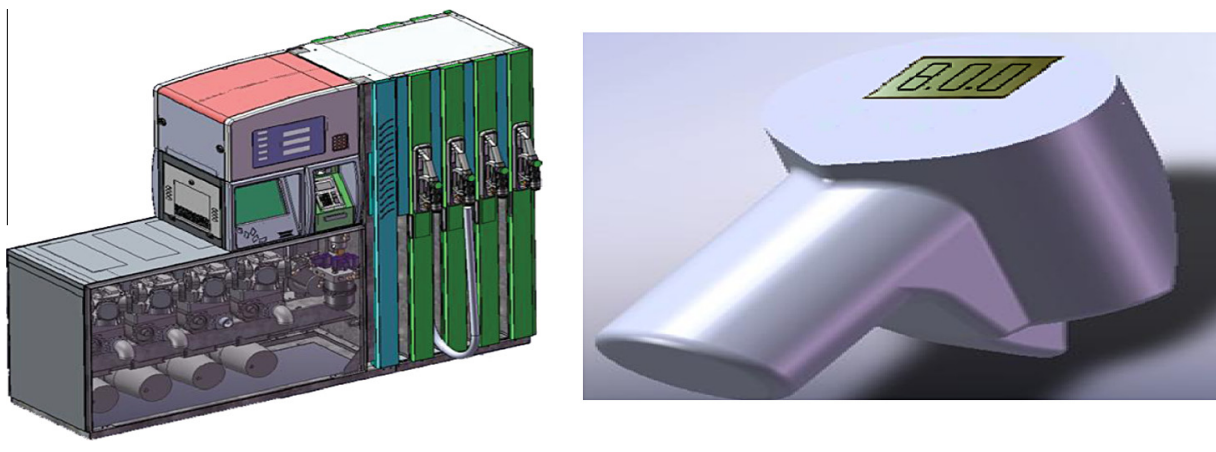

Fig. 6. Proposed innovations for the P5000 fuel pump. 


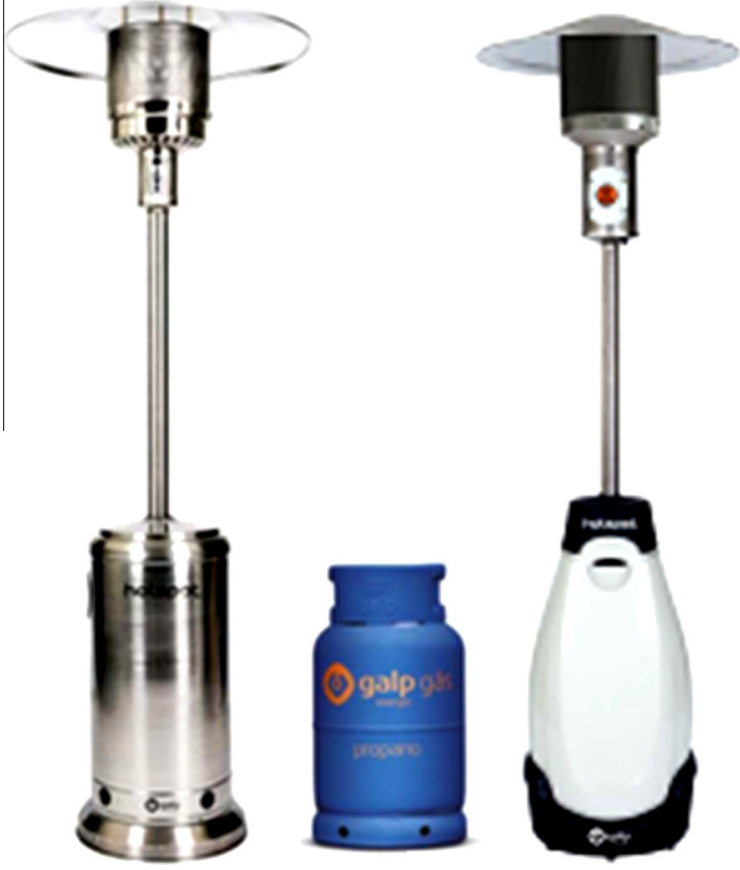

Fig. 7. Available hotspots.

- The winning application was included in the Galp Innovation Network, a unique platform for experts from GalpEnergia to develop projects of Research \& Development and Innovation.

IEIP objective was then an open assignment and students were supposed to design the equipment, a new low-cost gas terrace eater using Galp $11 \mathrm{~kg}$ propane cylinders, as well as the surrounding environment. The place of intervention was in the historical centre of Guimarães in a vacant building dated from the middle of the twentieth century and the adjacent square.

The assumptions for the preparation of proposals considered to the Contest "Hotspot Design" included:

- Technical Component.

- Design Component.

- Final Client Component (HORECA and households).

- International Market Component.

- Financial Component (cost and retail price with indicative ceilings).

The Hotspot design contest was held in two phases with the following rules:

- Phase 1 (from 1 October 2009 to 15 January 2010) corresponds to "Basic idea of the project" and should include the following:

- Report.

- Research carried out (e.g. attributes, innovative proposals, updates).

- Concept explanation.

- Technical operation principle.

- Description of materials used.

- Brief survey of costs (materials, manufacturing processes).

- Sketches/graphic design (representation of the proposed equipment).

- Assumptions/remarks.
One IEIP group successfully passed this phase and continued in the context until July.

- Phase 2 (1st March to 30th April 2010) is described as "Technical Design/Contract Specifications and should include the following:

- 3D CAD (Three Dimensional Computer Aided Design) Modeling and 2D Technical Drawings.

- Technical viability (e.g. demonstration of the principle of operation and feasibility).

- Specifications (List of parts and materials, possible suppliers, prices of materials, moulds, manufacturing method, per unit production cost quantities intervals).

- Projects that justify/support the concept through technical/ research studies with the target audience and optimize the MSRPs (Manufacturer's Suggested Retail Price) and Investments are welcomed.

The finalist IEIP group had an honor mention in the competition with the hotspot presented in Fig. 8.

\subsection{0/2011 year: description and objectives}

The company involved in 2010/2011 edition, Moldartpóvoa (www.moldartpovoa.com), is a small/medium enterprise whose main activities are the production of wood and aluminum frames.

There are three different materials, currently available on the market, for producing frames: wood, aluminum or plastic. Among these, wood is used for products considered as the noblest, but this raw material is associated to several problems such as its availability in quantity and cost, difficulties in obtaining rod with standard dimensions and the high number of process operations to obtain the final product. The market for aluminum frames has a huge variety of products and assembly systems, with excellent mechanical properties, but it is considered by consumers as a low quality product. On the value scale, plastic frames are the least quoted, having a very limited market impact.

Thermoplastic matrix composite materials have been used with success in several industries mainly because they combine excellent mechanical properties to a wide variety of finishing and

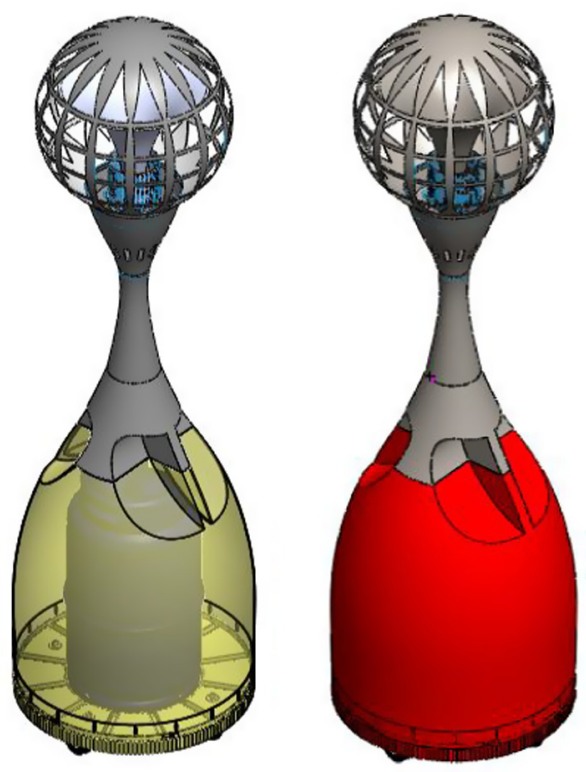

Fig. 8. IEIP group hotspot. 
textures, able to imitate numerous materials. However, this type of raw materials is not yet used in frames. There is an excellent opportunity to explore these types of materials in designing frames.

Under 2010-11 IEIP edition it was intended that the multidisciplinary teams address the following topics:

- Analysis and evaluation of the production system currently used by the company, proposing possible improvements, both in terms of automation and production organization.

- Proposal for a new product for the production of frames, which may use composite materials.

- Proposed changes to incorporate the proposed production the current production process.

- Assess the economic viability of the proposal.

The theme of this year was quite challenging to students from Electronics Engineering. In fact, in a new frame design there may not be a direct application of electronics. It was interesting to see how students came with new ideas: including LEDs in light frames, developing "intelligent" frames by including an on-off sensor to detect the presence of an individual and switch on the frame illumination, among other ideas. In fact, one of IEIP goals is to motivate students to work in open projects where they have to innovate and find out new applications for the subjects they have learnt so far.

\subsection{1/2012 year: description and objectives}

The Hydracooling Company (www.hydracooling.pt) was created in July 2009 and is dedicated to the development, production and marketing of commercial refrigeration products. Hydracooling exports $99 \%$ of its production, having as main markets France, England, Holland and Spain, and the firm is currently finalizing a product certification process for the North American markets.

The main objective of the "Hydrum" project is the development of commercial refrigeration equipment, which is a vertical refrigerated exhibitor, used to keep products such as drinks, sandwiches, dairy products, packed meat and fish (see Fig. 9). In the product development special attention must be given to the following as-

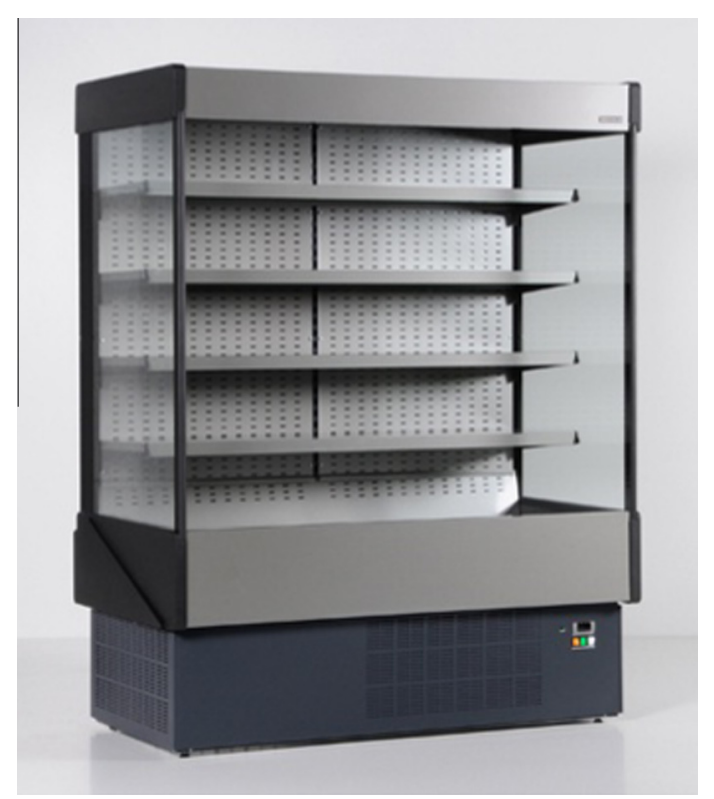

Fig. 9. Hydracooling Krypton W080 commercial display refrigerator. pects: energy efficiency, costs (raw materials and production), industrial design, and environmental problems.

The HYDRUM refrigerator should be developed so as to present a set of major advantages when compared to other existing models:

- Energy efficiency: nowadays there is a concern with respect to the costs of energy consumption, and there is a demand for increasingly efficient equipment. Typically, to optimize this type of products more efficient components are used, but have also higher costs. Another solution may be the machine design optimization so that the loss of "cold" is reduced to a minimum. When increasing the energy efficiency of a product leads to a price increase; it is necessary to evaluate the depreciation time that shall not exceed 12 months.

- Costs (raw materials and production): it is necessary to ensure that at least the cost of raw materials has an acceptable total value; otherwise the product shall no longer be competitive. Normally, when improving the referred aspects, if special attention is not given to the materials selection and components design, costs increases considerably.

- Industrial design: the project of this type of products has to be aware of aspects such as the ability to promote the products exposed in it; the ability to "pipeline": union of various equipment with each other.

- Environmental problems: environmental issues have enough relevance to the final consumer, which leads to food distribution companies to have a preference for "greener" products, showing this point as a sales argument.

Fig. 10 shows two of the proposed refrigerators.

\section{IEIP evaluation}

All over IEIP editions students referred a set of strengths and challenges during the project development. Integrating an interdisciplinary team and the consequent opportunity to interact with students from other courses, acquiring knowledge from other professional fields different from their own, is one of the most valued aspects of participation in experiments of this nature. Furthermore, the interdisciplinary nature, the possibility of practical application of content and proximity to the professional reality contribute to high motivation and commitment of the students during the project.

For the point of view of the teachers involved in the process, there is a common opinion that such multidisciplinary project based learning is a fruitful experience for the students. Especially when they are dealing with real-world problems and their innovations may be implemented in the partner industries.

Considering IEIP last edition, a deeper study regarding IEIP outcomes and students satisfaction was performed.

As mentioned before, the 2011/2012 edition involved the project and design of a display refrigerator. Four groups of eight students each were engaged in proposing solutions to this project. From the mechatronic perspective, the questions of this project were: selection the refrigerator unit components (compressor, evaporator, condenser and expansion valve) and its control in order to guarantee minimum energy expenditure; a front curtain to reduce thermal losses; and the lighting system of the display. Furthermore, they had to take care of the functional and aesthetic design of the refrigerator. The company proposing the project imposed some restrictions regarding the solutions to be presented, since it gave priority to off the shelf components.

Some novel and interesting concepts were proposed by the groups: adaptive lighting by using a sensor to measure ambient 

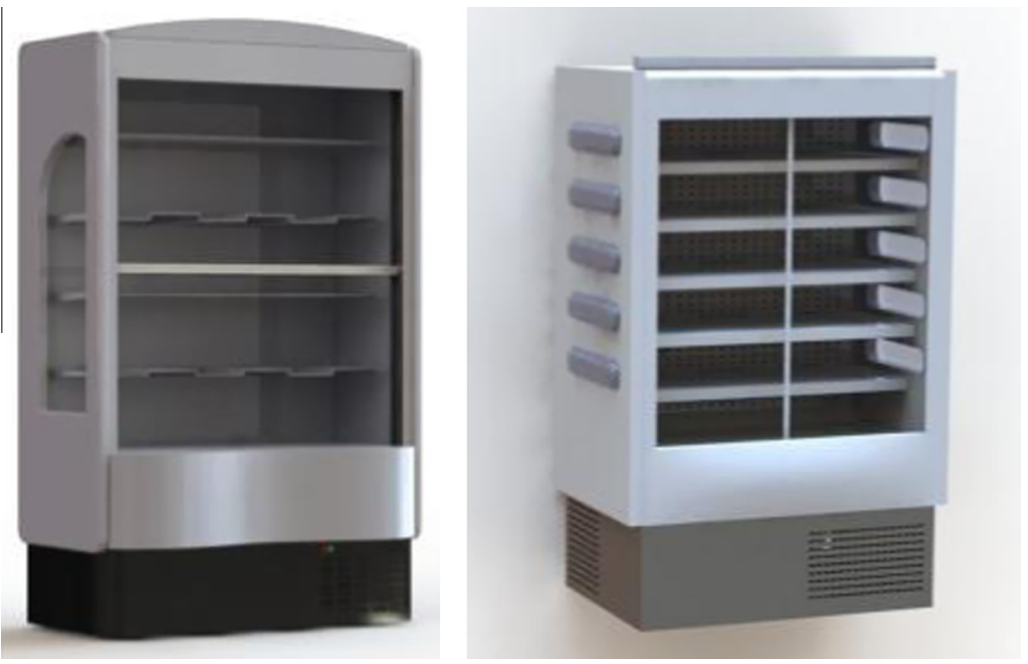

Fig. 10. Two proposed display refrigerators.

light; automatic curtains made of light materials, that open in the presence of people; compressors with variable drive speed to reduce energy consumption; plug and play shelves, which are equipped by their own led lighting; and, perhaps the most important, one group suggested a change in the refrigerant (instead of the usual R404A to a better R290) that would capitalize up to $15 \%$ reduction in energy consumption. These solutions (and specially the last one) were very well received by the company which was also globally satisfied with the overall performance of the groups.

The students have mixed opinions regarding their participation in IEIP. All of them state that the reason for choosing IEIP was the opportunity to try out a real world project and at the end $85 \%$ of the students had a positive opinion regarding the interaction with the company and $86 \%$ felt that IEIP was up to their expectations. On the other hand, $46 \%$ had negative opinions concerning the project evaluation and $31 \%$ though that the tutor/teacher support was not enough. These two points, evaluation grid and tutor/teacher support, are key topics to improve in the next edition.

The tutors/teachers opinion is that although the mechatronic questions were not very challenging, the outcome of this project was very satisfactory especially because of the transversal engineering competences (as described in the beginning of Section 2) that were gained.

Team management and project management are probably the most challenging soft skills that students must deal with in this type of projects. The project is very demanding in terms of size and duration. We are talking about eight students during 20 weeks requiring approximately $14 \mathrm{~h}$ of work per week, which is equivalent to 2.240 man-hours. This is a large project to be managed by inexperienced students but a great opportunity to experience the real management problems. Major difficulties are related to human resource planning, task planning and control and leadership problems. In order to prevent major problems tutors meet their teams once a week to check upon team work progress and furthermore there is a milestone approximately every 3 weeks so team work is monitored and controlled by presentations, report deliveries or meetings with the coordination team.

An extra challenge to students regarding team and project management in this type of approach is the difficulty for team members to find common spaces in their schedules to perform team work since team members are doing different engineering degrees. This is a problem that requires a solution that has been not found yet.
Some industry restrictions may also represent extra inconveniences. Too many students visiting the plant very frequently may be prohibitive since it requires industry personal to stay with the students and provide different sorts of information (students are quite avid in requiring all sorts of information, useful or not). This is a real issue especially because our policy is to keep the same company to all teams so they face exactly the same challenges and difficulties and therefore the competition seems fairer.

Although being normally attracted to students and so many times recommended by educators, there are some practical difficulties that must be discussed when real problems from industry are adopted in PBL approaches. First of all you cannot expect to match real project requirements to the any course syllabus. This means that students will not cover in the project all the technical competences that are listed in the course program. Students will develop competences (technical and transversal) not planned in any program but the positive side is that those competences are typically very useful in their future professional context. Some teachers do not deal very pacifically with this reality so many students must "learn" part of the syllabus (not covered in the project) on the old fashion way.

Regarding the coordination team, many are the issues to be attended especially because it is the heart of the whole process. If the coordination team does not work perfectly the whole process may be compromised. Since many courses are involved, the number of member in the coordination team is quite large. Normally the team is composed by teachers from each curricular unit supporting the project, plus tutors, researchers, entrepreneurship advisers and company representatives. Managing such a large and heterogeneous team is not easy at all and most of the soft skills (transversal competences) that we expect that students develop during the project are the same that the members of the coordination team also need to cultivate.

\section{Conclusions}

The Innovation and Entrepreneurship Integrated Project (IEIP) has been working for 5 years in University of Minho's School of Engineering. The active and positive participation of students that do not know each other, coming from different engineering areas, has been leading to successful projects, achieving very interesting prototypes.

During the five IEIP editions, there were five companies that proposed improvements for their products or new designs. The 
companies were PROHS and their bench sterilizer, Petrotec and their P5000 fuel pump, Galp that promoted a national contest to develop a new hotspot, Moldartpóvoa and their range of frames, and Hydracooling that proposed the development of a new high efficiency commercial refrigerator.

All the commercial products studied and developed in the IEIP required knowledge from different fields of engineering, namely Mechanics, Electronics and Computing, Polymers and Industrial Management. This reason by itself required the cooperation between the students of the various courses that compose each multidisciplinary group. As a consequence, students' technical skills are greatly enlarged and they acquired a multidisciplinary knowledge, because each student has to deal with various engineering lines. Another key issue is the possibility of practical application of content and the proximity to the professional reality.

The participating industries also took advantages of the IEIP: PROHS got projects for new, modern bench sterilizers; Petrotec got new ideas to implement in their new P5000 fuel pump; one of the Galp Hotspot contest proposals reached the final and received a honor mention; Moldartpóvoa got new ideas and new materials for their frames, including sensor and illumination integration; Hydracooling got new projects for high efficiency commercial display refrigerators, and is actually building a prototype.

Nevertheless, there are also some difficulties and problems. The main difficulties experienced by students are especially related to project management and interpersonal relationship. The main challenges include how to manage conflict situations, possibly caused by the divergence of opinions and ideas, the clash of positions and attitudes and the lack of communication within the group. Many of these problems are related to the multidisciplinary essence of the project. Also, in students' opinion, evaluation grid and tutor/teacher support must be reviewed and improved in the next edition.

\section{References}

[1] Graaff Ed, Kolmos A, editors. Management of change: implementation of problem-based and project-based learning in engineering. Rotterdam: Sense Publishers; 2007.

[2] Powell PC, Weenk W. Project-led engineering education. Utrecht: Lemma; 2003.

[3] Lima RM, Carvalho D, Flores MA, van Hattum-Janssen N. A case study on project led education in engineering: students' and teachers' perceptions. Eur J Eng Educ 2007;32:337-47.

[4] Carvalho D, Lima RM, Fernandes S. Learning in engineering: projects and interdisciplinary teams (title translated from portuguese - Aprendizagem em Engenharia: Projectos e Equipas Interdisciplinares). Presented at the $5^{\circ}$ Congresso Luso-Moçambicano de Engenharia (CLME'2008), Maputo Moçambique; 2008.

[5] UNESCO. Engineering: issues, challenges and opportunities for development United nations educational, scientific and cultural organization, Paris (France): 2010.

[6] Katajavuori N, Lindblom-Ylãnne S, Hirvonen J. The significance of practical training in linking theoretical studies with practice. Higher Educ 2006;51:439-64.

[7] Helle L, Tynjala P, Olkinuora E, Lonka K. 'Ain't nothin' like the real thing'. Motivation and study processes on a work-based project course in information systems design. Brit J Educ Psychol 2007;77:397-411. 2008/04/14 2007.

[8] Okudan GE, Rzasa SE. A project-based approach to entrepreneurial leadership education. Technovation 2006;26:195-210.

[9] Helle L, Tynjälä P, Olkinuora E. Project-based learning in post-secondary education - theory, practice and rubber sling shots. Higher Educ 2006;51:287-314.

[10] IEA. IEA Graduate attributes and professional competency profiles (Version 2) [International accord]; <http://www.washingtonaccord.org/IEA-Grad-AttrProf-Competencies-v2.pdf> [29.04.12]

[11] Harrison GP, Macpherson DE, Williams DA. Promoting interdisciplinarity in engineering teaching. Eur J Eng Educ 2007;32:285-93.

[12] Gibb A. In pursuit of a new 'enterprise' and 'entrepreneurship' paradigm for learning: creative destruction, new values, new ways of doing things and new combinations of knowledge. Int J Manage Rev 2002;4:213-69.

[13] CCE. Aplicar o Programa Comunitário de Lisboa: Promover o espírito empreendedor através do ensino e da aprendizagem (COMISSÃO DAS COMUNIDADES EUROPEIAS); 2006. <http://eur-lex.europa.eu/LexUriServ/ LexUriServ.do?uri=COM:2006:0033:FIN:PT:PDF> [15.04.10] 